\section{Prevalence and determinants of burnout syndrome and depression among medical students at Qassim University, Saudi Arabia}

\author{
Abdulmajeed A. Alkhamees, MD, SSC-Psych, \\ Naif S. Alaqil, MS, Ali S. Alsoghayer, MS, \\ Basil A. Alharbi, MS.
}

\section{ABSTRACT}

Objectives: To investigate the prevalence and determinants of burnout syndrome and depression among medical students at Unaizah College of Medicine (UCM), Qassim University, Qassim, Kingdom of Saudi Arabia (KSA).

Methods: A cross-sectional study of all Saudi medical students studying at UCM, Qassim University, Al Qassim, KSA, between February to March 2020.

Results: Of the total 305 students sampled, 153 $(50.2 \%)$ fit the category of depression. Concerning burnout, only $5.6 \%$ of the total population met the Maslach Burnout Inventory diagnostic criteria for burnout, with those determined to have burnout having ranked high on the emotional exhaustion and cynicism subscales, and low on the academic efficacy subscale. Male was strongly associated with burnout, while female gender and raising children were strongly associated with the presence of depression. Emotional exhaustion and high cynicism as determinants of burnout elevate the risk of depression.

Conclusion: Our results highlight the high rate of depression and burnout, as well as the need for psychological intervention programs at medical schools to prevent the deterioration of student's mental health that has been associated with advancement in medical school.

Keywords: burnout syndrome, depressive symptoms, Maslach burnout inventory, medical students, Saudi Arabia

Saudi Med J 2020; Vol. 41 (12): 1375-1380 doi: 10.15537/smj.2020.12.25427

$\mathrm{B}$ urnout and depression have become a significant mental health concerns at medical schools. There is a body of evidence showing that upcoming medical health professionals suffer from alarming rates of burnout and depression and that they continue to be affected after graduation and into professional life. ${ }^{1}$
Burnout is defined as as a psychological condition involving emotional exhaustion, depersonalization, and a reduced sense of personal accomplishment that occurred among different professionals who work with other people in challenging situations. ${ }^{2}$ There was a suggestion that almost half of medical students experienced burnout, one-quarter of them have depression, and many experienced chronic anxieties as well as poor mental quality of life. ${ }^{3}$

Despite this, relatively few students seek help. Students underutilize the available support services, partially due to concern about the associated social and professional stigmas. ${ }^{4} \mathrm{~A}$ potential consequence of such concern is the failure of students to seek adequate care might affect the quality of care provided for patients. Therefore, it is clear that the early address of mental health issues during medical school is of most importance.

Data for burnout and depression, their risk factors, and correlates among Saudi medical students are scarce. The published studies are primarily concerned with burnout. ${ }^{5}$ Therefore, there is a crucial need for further studies to explore the determinants of depression and burnout, especially in Qassim, KSA, in a newly developing college of medicine with fewer resources. This study aims to assess the prevalence of burnout and depression, risk factors, and relationship among medical students in Unaizah College of Medicine (UCM), Qassim, Kingdom of Saudi Arabia (KSA).

Methods. This study follows a cross-sectional study design that had been carried out among Saudi medical students studying at UCM, Qassim University, Qassim, KSA, between February and March 2020. It has a 6-year MD degree plan comprised of 3 basic years (premed, MD1, MD2), 2 clinical years (MD3, MD4), and one year in an internship program. Every Saudi medical student from all 6 academic years at UCM was asked to participate in the study $(\mathrm{N}=350)$. Out of 350 potential participants, only 305 responded. Students outside of UCM were excluded.

Study procedure. Data was collected in the classrooms. Instructors were asked to make use of a few minutes of class time to clarify the study to the students and to complete the questionnaire. An electronic version of the questionnaires was circulated using the class what's app

Disclosure. Authors have no conflict of interests, and the work was not supported or funded by any drug company. 
group. A copy of the informed consent form was also sent together with the questionnaires. Participants were informed that their data would be kept confidential, and it will be used for research purposes only. The protocol of the study was approved by the Qassim University Institutional Review Board (No.19-08-05). Students who did not complete the questionnaire or did not sign the informed consent forms were excluded from data analyses.

Study instrument. Besides the sociodemographic and academic information of the participants, the current study data was collected via 2 well-known and validated questionnaires: the Maslach burnout inventory-student survey (MBI-SS), and the patient health questionnaire (PHQ-9). ${ }^{6,7}$ The MBI-SS is a 15-item instrument measuring burnout levels among students. It consists of 3 subscales: emotional exhaustion (EX, 5 items), cynicism (CY, 4 items), and academic efficacy (AE, 6 items). As previously proposed by Maslach and Jackson, burnout syndrome severity was expressed in percentile scores. The indicator of high EX and high CY was determined to be mean scores above the $66^{\text {th }}$ percentile (P66), and the indicator of low AE was a mean score below the $33^{\text {rd }}$ percentile (P33). Participants with exhaustion and cynicism mean values exceeding P66 and professional efficacy results lower than P33 were considered to have burnout syndrome.

Depressive symptoms were assessed using the patient health questionnaire (PHQ-9), which is a selfadministered tool comprised of 9 items (numbered from 1-9), each scored on a 4-point Likert scale from $0-3$ as follows: $0=$ not at all; $1=$ several days; $2=$ more than half the days; and $3=$ nearly every day. The scores for symptom severity were 5-9 for mild, 10-14 for moderate, 15-19 for moderately severe, and 20-27 for severe. Participants with a PHQ-9 score $\geq 10$ were considered to be depressed as used previously in literature. ${ }^{8}$

Data analysis. The analysis was carried out using the Statistical Package for Social Sciences for Windows, version 22.0 (IBM Corp., Armonk, NY, USA). Descriptive analysis was conducted, and the results for categorical variables presented using frequencies and percentages, and those for continuous variables presented using means and standard deviation. Univariate analysis was conducted with the generation of unadjusted risk ratios to determine factors associated with burnout and depression. Adjusted odds ratios for the variables were determined using a backward stepwise logistic regression that was also aimed at finding the key predictors of burnout and depression among the university students sampled.
Results. In line with the methodology previously described, a total of 305 eligible university students were recruited into the study sociodemographic characteristics and prevalence of depression and burnout syndrome among UCM described in (Table 1).

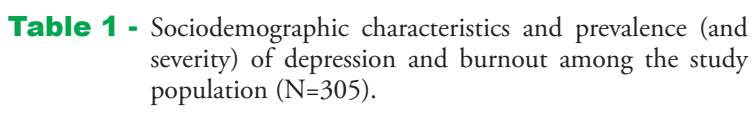

Table 1 - Sociodemographic characteristics and prevalence (and severity) of depression and burnout among the study population $(\mathrm{N}=305)$.

\begin{tabular}{|c|c|}
\hline Variables & n $(\%)$ \\
\hline \multicolumn{2}{|l|}{ Age (years) } \\
\hline $18-21$ & $122(40.0)$ \\
\hline $22-25$ & $175(57.4)$ \\
\hline $26-29$ & $7(2.3)$ \\
\hline$>29$ & $1 \quad(0.3)$ \\
\hline \multicolumn{2}{|l|}{ Gender } \\
\hline Male & $144(47.2)$ \\
\hline Female & $161(52.8)$ \\
\hline Weight $(\mathrm{kg})$ mean $\pm \mathrm{SD}$ & $69.0 \pm 18.5$ \\
\hline Height $(\mathrm{cm})$ mean $\pm S D$ & $165.9 \pm 9.8$ \\
\hline Body mass index $\left(\mathrm{kg} / \mathrm{m}^{2}\right)$ mean $\pm \mathrm{SD}$ & $24.9 \pm 5.6$ \\
\hline \multicolumn{2}{|l|}{ Academic year } \\
\hline Premed & $63(20.7)$ \\
\hline MD1 & $50(16.4)$ \\
\hline MD2 & $67(22.0)$ \\
\hline MD3 & $73(23.9)$ \\
\hline MD4 & $52(17.0)$ \\
\hline \multicolumn{2}{|l|}{ Marital status } \\
\hline Single & $293(96.1)$ \\
\hline Married & $12(3.9)$ \\
\hline \multicolumn{2}{|l|}{ Raising children at time of study } \\
\hline Yes & 11 (3.6) \\
\hline No & $294(96.4)$ \\
\hline \multicolumn{2}{|l|}{ Who respondents live with } \\
\hline Family & $279(91.5)$ \\
\hline Friends & $6(2.0)$ \\
\hline Alone & $20 \quad(6.6)$ \\
\hline \multicolumn{2}{|l|}{ Severity of depression $(n=153)$} \\
\hline Moderate depression & $73(47.7)$ \\
\hline Moderately severe depression & $39(25.5)$ \\
\hline Severe depression & $41(26.8)$ \\
\hline \multicolumn{2}{|l|}{ Burnout syndrome* } \\
\hline Yes & $17 \quad(5.6)$ \\
\hline No & $288(94.4)$ \\
\hline \multicolumn{2}{|l|}{ Burnout subscales } \\
\hline High emotional exhaustion & $124(40.7)$ \\
\hline High cynicism & $73(23.9)$ \\
\hline Low academic efficacy & $91(29.8)$ \\
\hline
\end{tabular}


Burnout syndrome and sociodemographic factors. A closer look at the relations between burnout and sociodemographic factors indicated that only age, gender, and students' academic year in the university had effects on the existence of burnout at the time of the study (Table $2 \& 3$ ). Students aged between 18-21 years had a reduced risk of having burnout with a crude/unadjusted odds ratio (COR) of 0.61 (95\% CI: $0.21-1.77)$ and an adjusted odds ratio (AOR) of 0.34 (95\% CI: 0.08-1.51). Similarly, males (COR $=0.06$, 95\% CI: $0.01-0.48)$ and those in premed $(\mathrm{COR}=0.81$, 95\% CI: 0.23-2.93) had lower chances of developing burnout compared with females and those in clinical classes respectively when focusing on the unadjusted $\mathrm{OR}$ as the risk determination parameter. However, when the adjusted OR is considered, premed students were more likely than their peers in clinical to develop burnout with an AOR of 1.94 (95\% CI: 0.32-11.64).

Relationships between burnout syndrome and depression. Concerning the association between sociodemographic factors and depression, only age, gender, raising children, and academic year had any statistically significant association on the presence of depression ranging from moderate to moderately severe and severe depression $(p<0.05)$. The individual was determined to have depression if he/she had at least moderate depression with a score of at least 10 on the PHQ ( $\mathrm{n}=153)$. Students 22 years or older had higher unadjusted $(\mathrm{COR}=1.66)$ and adjusted $(\mathrm{AOR}=1.34)$ risks of depression than those younger than 22 years (Table 3). Similarly, females had higher chances of coming down with depression than males based on both unadjusted $(\mathrm{COR}=4.22)$ and adjusted $(\mathrm{AOR}=4.77)$ $\mathrm{OR}$. Respondents who were in their clinical year were significantly more likely to have depression than their counterparts in premed classes. On the other hand, those who were not currently raising children were significantly less likely to have depression than those who are currently raising children.

Going further to observe the relations between depression and burnout, Table 4 shows the influence of high emotional exhaustion, high cynicism, and low academic efficacy on depression.

Table 2 - Relations between burnout, depression, and socio-demographic factors ( $\mathrm{N}=305)$.

\begin{tabular}{|c|c|c|c|c|c|c|c|}
\hline \multirow[t]{2}{*}{ Variables } & \multicolumn{2}{|c|}{ Burnout } & \multirow[t]{2}{*}{ Total } & \multicolumn{2}{|c|}{ Unadjusted OR } & \multicolumn{2}{|c|}{ Adjusted OR } \\
\hline & Yes $(n=17)$ & No $(n=288)$ & & OR & $95 \% \mathrm{CI}$ & OR & $95 \% \mathrm{CI}$ \\
\hline \multicolumn{8}{|l|}{ Age (years) } \\
\hline $18-21$ & $5(29.4)$ & $117(40.6)$ & 122 & 0.61 & \multirow{2}{*}{$0.21-1.77$} & \multirow{2}{*}{0.34} & \multirow{2}{*}{$\begin{array}{c}0.08- \\
1.51\end{array}$} \\
\hline$\geq 22$ & $12(70.6)$ & $171(59.4)$ & 183 & 1 & & & \\
\hline \multicolumn{8}{|l|}{ Gender } \\
\hline Male & $1 \quad(5.9)$ & $143(49.7)$ & 144 & 0.06 & \multirow{2}{*}{$0.01-0.48$} & \multirow{2}{*}{0.06} & \multirow{2}{*}{$\begin{array}{c}0.01- \\
0.46\end{array}$} \\
\hline Female & $16(94.1)$ & $145(50.3)$ & 161 & 1 & & & \\
\hline \multicolumn{8}{|l|}{ Marital status } \\
\hline Single & $17(100)$ & $276(95.8)$ & 293 & \multirow{2}{*}{ NA } & \multirow{2}{*}{ NA } & \multirow{2}{*}{ NA } & \multirow{2}{*}{ NA } \\
\hline Married & $0(0.0)$ & $12(4.2)$ & 12 & & & & \\
\hline \multicolumn{8}{|l|}{ Academic year } \\
\hline Premed & $3(17.6)$ & $60(20.8)$ & 63 & 0.81 & \multirow{2}{*}{$0.23-2.92$} & \multirow{2}{*}{1.94} & \multirow{2}{*}{$\begin{array}{l}0.32- \\
11.64\end{array}$} \\
\hline Medicine & $14(82.4)$ & $228(79.2)$ & 242 & 1 & & & \\
\hline \multicolumn{8}{|l|}{ Raising children } \\
\hline Yes & $0(0.0)$ & $11 \quad(3.8)$ & 11 & \multirow{2}{*}{ NA } & \multirow{2}{*}{ NA } & \multirow{2}{*}{ NA } & \multirow{2}{*}{ NA } \\
\hline No & $17(100)$ & $277(96.2)$ & 294 & & & & \\
\hline \multicolumn{8}{|l|}{ Living place } \\
\hline Family and friends & $17(100)$ & $268(93.1)$ & 285 & \multirow{2}{*}{ NA } & \multirow{2}{*}{ NA } & \multirow{2}{*}{ NA } & \multirow{2}{*}{ NA } \\
\hline Alone & $0(0.0)$ & $20 \quad(6.9)$ & 20 & & & & \\
\hline
\end{tabular}

Values are presented as numbers and percentages (\%). OR: odds ratio 
Burnout syndrome and depression ... Alkhamees et al

Table 3 - Relationship between sociodemographic factors and depression (patient healthcare questionnaire) (N=305).

\begin{tabular}{|c|c|c|c|c|c|c|c|}
\hline \multirow[t]{2}{*}{ Variables } & \multicolumn{2}{|c|}{ Depression } & \multirow[t]{2}{*}{ Total } & \multicolumn{2}{|c|}{ Unadjusted OR } & \multicolumn{2}{|c|}{ Adjusted OR } \\
\hline & Yes $(n=153)$ & No $(n=152)$ & & OR & $95 \% \mathrm{CI}$ & OR & $95 \% \mathrm{CI}$ \\
\hline \multicolumn{8}{|l|}{ Age (years) } \\
\hline$\geq 22$ & $101(55.2)$ & $82(44.8)$ & 183 & $1.66^{*}$ & \multirow{2}{*}{$1.04-2.63$} & \multirow{2}{*}{1.34} & \multirow{2}{*}{$0.74-2.44$} \\
\hline $18-21$ & $52(42.6)$ & $70(57.4)$ & 122 & 1 & & & \\
\hline \multicolumn{8}{|l|}{ Gender } \\
\hline Female & $107(66.5)$ & $54(33.5)$ & 161 & $4.22^{*}$ & \multirow{2}{*}{$2.61-6.82$} & \multirow{2}{*}{$4.77^{*}$} & \multirow{2}{*}{$2.88-7.91$} \\
\hline Male & $46(31.9)$ & $98(68.1)$ & 144 & 1 & & & \\
\hline \multicolumn{8}{|l|}{ Marital status } \\
\hline Married & $9(75.0)$ & $3(25.0)$ & 12 & \multirow{2}{*}{3.10} & \multirow{2}{*}{$0.82-11.70$} & \multirow{2}{*}{1.48} & \multirow{2}{*}{$0.32-6.84$} \\
\hline Single & $144(49.1)$ & $149(50.9)$ & 293 & & & & \\
\hline \multicolumn{8}{|l|}{ Raising children } \\
\hline No & 143 (48.6) & $151(51.4)$ & 294 & \multirow{2}{*}{$0.09^{*}$} & \multirow{2}{*}{$0.01-0.75$} & \multirow{2}{*}{$0.07^{*}$} & \multirow{2}{*}{$0.01-0.61$} \\
\hline Yes & $10(90.9)$ & $1 \quad(9.1)$ & 11 & & & & \\
\hline \multicolumn{8}{|l|}{ Academic year } \\
\hline Med & $130(53.7)$ & $112(46.3)$ & 242 & \multirow{2}{*}{$2.02^{*}$} & \multirow{2}{*}{$1.14-3.58$} & \multirow{2}{*}{1.73} & \multirow{2}{*}{$0.84-3.57$} \\
\hline Premed & $23(36.5)$ & $40(63.5)$ & 63 & & & & \\
\hline \multicolumn{8}{|l|}{ Living place } \\
\hline Alone & $11(55.0)$ & $9(45.0)$ & 20 & \multirow{2}{*}{1.23} & \multirow{2}{*}{$0.49-3.06$} & \multirow{2}{*}{1.81} & \multirow{2}{*}{$0.66-4.95$} \\
\hline Family $\&$ friends & $142(49.8)$ & $143(50.2)$ & 285 & & & & \\
\hline
\end{tabular}

Table 4 - Relations between burnout subscales and depression (patient healthcare questionnaire) (N=305).

\begin{tabular}{|c|c|c|c|c|c|c|c|}
\hline \multirow[t]{2}{*}{ Subscales } & \multicolumn{2}{|c|}{ Depression } & \multirow[t]{2}{*}{ Total } & \multicolumn{2}{|c|}{ Unadjusted OR } & \multicolumn{2}{|c|}{ Adjusted OR } \\
\hline & Yes $(n=153)$ & No $(n=152)$ & & OR & $95 \% \mathrm{CI}$ & OR & $95 \% \mathrm{CI}$ \\
\hline \multicolumn{8}{|c|}{ High emotional exhaustion } \\
\hline Yes & $100(80.6)$ & $24(19.4)$ & 124 & $10.06^{*}$ & \multirow{2}{*}{$5.81-17.41$} & \multirow{2}{*}{$6.54^{*}$} & \multirow{2}{*}{$3.59-11.90$} \\
\hline No & $53(29.3)$ & $128(70.7)$ & 181 & 1 & & & \\
\hline \multicolumn{8}{|c|}{ High cynicism } \\
\hline Yes & $64(87.7)$ & $9(12.3)$ & 73 & $11.43^{*}$ & \multirow{2}{*}{$5.42-24.10$} & \multirow{2}{*}{$4.98^{*}$} & \multirow{2}{*}{$2.21-11.22$} \\
\hline No & $89(38.4)$ & $143(61.6)$ & 232 & 1 & & & \\
\hline \multicolumn{8}{|c|}{ Low academic efficacy } \\
\hline Yes & $45(49.5)$ & $46(50.5)$ & 91 & 0.96 & \multirow{2}{*}{$0.59-1.57$} & \multirow{2}{*}{1.26} & \multirow{2}{*}{$0.70-2.29$} \\
\hline No & $108(50.5)$ & $106(49.5)$ & 214 & 1 & & & \\
\hline
\end{tabular}


Discussion. In the current study, we assessed the prevalence of burnout as well as depression among medical students at UCM using the MBI and the PHQ-9. The estimated prevalence was 5.6\% and 50.2\%, respectively. High emotional exhaustion and high cynicism as determinants of burnout were significantly correlated with depressive symptoms.

The estimated depression prevalence in the current study is considered within the range of similar previous international and national studies. Globally, previous studies showed that $9.3-55.9 \%$ of medical students exhibit depressive symptoms. ${ }^{9}$ In Oman, the reported prevalence of depression among medical students of $24.5 \%$ was almost half of ours. ${ }^{10}$ Locally, a recently published study from Bisha, KSA, showed that the prevalence of depressive symptoms among medical students was $26.8 \% .{ }^{11}$ Such results emphasize that depression is highly prevalent in this distinct population who might not seek mental health services because of fear of exposure and stigma.

For burnout, the reported prevalence in our study was in agreement with a previous study conducted in Omani medical students where they reported the prevalence of burnout to be $7.4 \%$. Contrary to our findings, a recent local study reported the prevalence to be $67.1 \% .^{5}$ The varying reported levels and differences of depression and burnout could be attributed to the variety of instruments used and varying social factors. Previous study from Oman found that preclinical students have more depression and anxiety compared to students in the clinical phase. ${ }^{10}$ Such findings are considered in contrast to ours because despite being statistically significant only in unadjusted OR, clinical students in our study showed a higher prevalence of depression compared to preclinical ones.

The transition to wards in clinical years can be frightening and stress-inducing. Training-related maltreatment and exploitation by superiors were suggested explanations of why medical students become more disposed to depression in clinical years. ${ }^{12}$ Also, most medical students handle difficult cases and face dying patients for the first time during the clinical years. Moreover, medical students are presented with more tasks and therefore experience an increased level of stress as they progress through medical training.

There is a complex fluctuation in the relationship between burnout and gender. In the current study, female students had higher scores in burnout syndrome. In contrast, $\mathrm{Al}$-Alawi et $\mathrm{al},{ }^{10}$ reported that the score was higher among males, but the difference was statically non-significant. Additionally, studies from KSA were inconsistent in this regard. ${ }^{5,13}$ Number of studies have reported that females are more prone to developing high levels of burnout; nevertheless, the cause remains unclear. The suggested explanation was that compared to males, females have a higher probability of viewing these faced difficulties as stressful. ${ }^{14}$ In KSA, cultural, social, and religious factors could precipitate greater levels of burnout among female medical students. Female students trying to preserve traditional family dynamics may expend more effort as they try to manage their time with family and with their studies, which can increase stress and burnout prevalence.

There is a body of evidence suggests that the prevalence of burnout is significantly higher among clinical compared to preclinical students, a finding that is similar to ours. ${ }^{15}$ However, in our case, the difference was non-significant. In disagreement with these results, other studies report that the burnout level is higher in the preclinical compared to the clinical students. ${ }^{14}$ Burnout slowly evolves over the years of medical school as throughout the preclinical and clinical stages; students are expected to have more patient responsibilities and be faced with an increased volume of new materials.

Study limitations. The present studies naturally include the small sample size, and the sample was taken from only one medical college. Therefore, the results cannot be generalized to all the medical students in KSA and a large sample of multicentric approach studies is needed. The nature of cross-sectional design does not allow explaining causation and temporality of burnout and depression; therefore, prospective cohort studies would be more appropriate to address this limitation. Aside from these limitations, the strengths of the current study represented in that it used validated questionnaires that have shown good internal consistency.

In conclusion, in this cross-sectional study among Saudi medical students at UCM, Qassim, KSA, the prevalence of burnout syndrome, and depression symptoms in particular, was found to be high. Regarding correlates, after adjustment, the male gender was strongly associated with burnout, while female gender and raising children were strongly associated with the presence of depression. Emotional exhaustion and high cynicism as determinants of burnout elevated the risk of depression.

Our results highlight the need for psychological intervention programs for students in medical school. Correlates for depression, including burnout and raising children, should be identified early to limit progression to depression among medical students. 
Acknowledgment. The authors gratefully acknowledge all respondents and participants who helped circulate the questionnaire during the process of data collection. Also we would like to thank Cambridge Proofreading (www.proofreading.org) for English language editing.

Received 24th June 2020. Accepted 17th September 2020.

From the Department of Medicine (Alkhamees), College of Medicine and Medical Sciences; and from the College of Medicine and Medical Sciences (Alaqil, Alsoghayer, Alharbi), Qassim University, Al Qassim, Kingdom of Saudi Arabia.

Address correspondence and reprints request to: Dr. Abdulmajeed A. Alkhamees, Department of Medicine, College of Medicine and Medical Sciences, Qassim University,AlQassim,KingdomofSaudiArabia.E-mail:A.alkhamees@qu.edu.sa ORCID ID: https://orcid.org/0000-0003-2808-2370

\section{References}

1. Mousa OY, Dhamoon MS, Lander S, Dhamoon AS. The MD blues: under-recognized depression and anxiety in medical trainees. PLoS One 2016; 11: e0156554.

2. Plutchik R. Burnout: the cost of caring-by Christina Maslach. Psychiatr Serv 1982; 34: 650.

3. Dyrbye LN, Thomas MR, Shanafelt TD. Systematic review of depression, anxiety, and other indicators of psychological distress among U.S. and Canadian medical students. Acad Med 2006; 81: 354-373.

4. Chew-Graham CA, Rogers A, Yassin N. 'I wouldn't want it on my CV or their records': medical students' experiences of help-seeking for mental health problems. Med Educ 2003; 37: 873-880.

5. Almalki SA, Almojali AI, Alothman AS, Masuadi EM, Alaqeel MK. Burnout and its association with extracurricular activities among medical students in Saudi Arabia. Int J Med Educ 2017; 8: 144-150.

6. Yavuz G, Dogan N. Maslach burnout inventory-student survey (MBI-SS): a validity study. Procedia Soc Behav Sci 2014; 116: 2453-2457.
7. Kroenke K, Spitzer RL, Williams JB. The PHQ-9: validity of a brief depression severity measure. J Gen Intern Med 2001; 16: 606-613.

8. AlHadi AN, AlAteeq DA, Al-Sharif E, Bawazeer HM, Alanazi $\mathrm{H}$, AlShomrani AT, et al. An arabic translation, reliability, and validation of patient health questionnaire in a Saudi sample. Ann Gen Psychiatry 2017; 16: 32.

9. Rotenstein LS, Ramos MA, Torre M, Segal JB, Peluso MJ, Guille C, et al. Prevalence of depression, depressive symptoms, and suicidal ideation among medical students: a systematic review and meta-analysis. JAMA 2016; 316: 2214-2236.

10. Al-Alawi M, Al-Sinawi H, Al-Qubtan A, Al-Lawati J, Al-Habsi A, Al-Shuraiqi $\mathrm{M}$, et al. Prevalence and determinants of burnout syndrome and depression among medical students at Sultan Qaboos University: a cross-sectional analytical study from Oman. Arch Environ Occup Health 2019; 74: 130-139.

11. Al-Shahrani MS, Alharthi MH, Alamri MS, Ibrahim ME. Prevalence of depressive symptoms and its predicted factors among medical students in University of Bisha, Saudi Arabia. Int J Ment Health Syst 2020; 9: 1-17.

12. Roberts LW, Warner TD, Lyketsos C, Frank E, Ganzini L, Carter D. Perceptions of academic vulnerability associated with personal illness: a study of 1,027 students at nine medical schools. Compr Psychiatry 2001; 42: 1-15.

13. Altannir Y, Alnajjar W, Ahmad SO, Altannir M, Yousuf F, Obeidat A, et al. Assessment of burnout in medical undergraduate students in Riyadh, Saudi Arabia. BMC Med Educ 2019; 19: 34.

14. Fares J, Al Tabosh H, Saadeddin Z, El Mouhayyar C, Aridi H. Stress, burnout and coping strategies in preclinical medical students. N Am J Med Sci 2016; 8: 75-81.

15. Ishak W, Nikravesh R, Lederer S, Perry R, Ogunyemi D, Bernstein C. Burnout in medical students: a systematic review. Clin Teach 2013; 10: 242-245. 